$$
\begin{aligned}
& \text { ANL/MSD/CP--89719 } \\
& \text { CONF- } 960994--15
\end{aligned}
$$

HRTEM ANALYSIS OF SOLID PRECIPITATES IN Xe-IMPLANTED ALUMINUM*

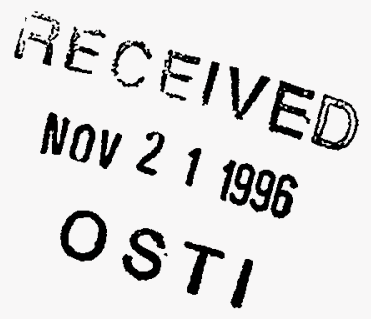

Charles W. Allen and Robert Birtcher

Materials Science Division

Argonne National Laboratory

Argonne, IL 60439

N. Ishikawa, K. Furuya, and M. Awaji

National Research Institute for Metals

Sakura, Tsukuba, 305 Japan

September 1996

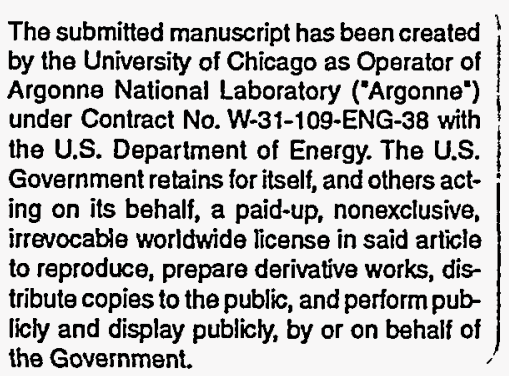

the Government.

Submitted to the Ion Beam Modification of Materials, September 1-6, 1996, Albuquerque, NM.

*Work supported by the U. S. Department of Energy, BES-Materials Sciences, under Contract W-31-109-Eng-38. 


\section{DISCLAIMER}

This report was prepared as an account of work sponsored by an agency of the United States Government. Neither the United States Government nor any agency thereof, nor any of their employees, makes any warranty, express or implied, or assumes any legal liability or responsibility for the accuracy, completeness, or usefulness of any information, apparatus, product, or process disclosed, or represents that its use would not infringe privately owned rights. Reference herein to any specific commercial product, process, or service by trade name, trademark, manufacturer, or otherwise does not necessarily constitute or imply its endorsement, recommendation, or favoring by the United States Government or any agency thereof. The views and opinions of authors expressed herein do not necessarily state or reflect those of the United States Government or any agency thereof. 


\section{DISCLAIMER}

Portions of this document may be illegible in electronic image products. Images are produced from the best available original document. 


\title{
HRTEM ANALYSIS OF SOLD PRECIPITATES IN XE-IMPLANTED ALUMINUM
}

Nobuhiro ISHIKAWA ${ }^{a+}$, Mitsuhiro AWAJ ${ }^{a}$, Kazuo FURUYA ${ }^{a}$, Robert C. BIRTCHER ${ }^{b}$ and Charles W. ALLEN ${ }^{b}$

${ }^{a}$ National Research Institute for Metals, Sakura, Tsukuba, 305 JAPAN

${ }^{b}$ Materials Science Division, Argonne National Laboratory, Argonne, IL 60439, USA

+phone: 81-298-53-1182,FAX: 81-298-53-1199, e-mail: ishinobu@nrim.go.jp

\begin{abstract}
High-resolution transmission electron microscopy (HRTEM) was carried out to determine the shape and atomic arrangement of solid Xe precipitates in Al. Polycrystalline Al TEM specimens were implanted with $30 \mathrm{keV} \mathrm{Xe}{ }^{+}$at room temperature to a dose of $3 \times 10^{20}$ ions $/ \mathrm{m}^{2}$ and were subsequently annealed at $523 \mathrm{~K}$. Below a size of approximately $4 \mathrm{~nm}$ in diameter, Xe precipitates are solid with an FCC crystal structure that are mesotacticly aligned with the Al lattice. In HRTEM along [011] projection, the difference in the lattice parameters of solid Xe and $\mathrm{Al}$ produces a precipitate image dominated by a two-dimensional Moiré pattern that repeats in both the $\langle 001\rangle$ and $\langle 111>$ directions every $3 \mathrm{Al}$ (or $2 \mathrm{Xe}$ ) lattice spacings. Multislice image simulations, using a three-dimensional atomic model, demonstrates that the precipitates are tetradecahedra with faces parallel to the dense $\{111\}$ planes and the $\{100\}$ planes. Off-Bragg illumination of the precipitates minimizes $\mathrm{Al}$ lattice fringes and generates precipitate images which are in good agreement with the model.
\end{abstract}

Key words: Solid Xe, implantation, precipitation, High-resolution electron microscopy, Moiré patterns, tetradecahedral precipitates, Off-Bragg illumination 


\section{Introduction}

The behavior of inert gases in materials has been studied extensively over the past decades because of material problems associated with the development of fusion and fission reactors [1-2]. The sputter deposition, cleaning and thinning of materials by ions, commonly used in semiconductor industries, have also raised scientific, as well as technical concerns related to the behavior of heavier inert gases implanted by these processes. All the inert gases are insoluble and precipitate. At room temperature, inert gas precipitates less than $4 \mathrm{~nm}$ in diameter are crystalline solids mesotacticly aligned with the surrounding matrix. Birtcher et. al [3-5] have reported for the case of $\mathrm{Kr}$ and $\mathrm{Xe}$ in $\mathrm{Ni}$ and $\mathrm{Al}$ that the difference in lattice parameters between the precipitate and the matrix varies with precipitate size and reaches as much as $50 \%$, depending on the combination of gases and metal matrix. These observations were carried out using electron diffraction in the transmission electron microscope (TEM). With the advent of high-resolution electron microscopy (HRTEM) with image resolution approaching to $0.1 \mathrm{~nm}$, attempts have been made to determine the shape and topotactical alignment of the inert gas and other insoluble precipitates [6-9]. Gråbæk et al. [10] and Xiao et al. [11] investigated $\mathrm{Tl}$ and $\mathrm{Pb}$ inclusions in $\mathrm{Al}$, respectively, and showed that the shape of inclusions is an octahedron bounded by $\{111\}$ truncated by a with small amount of $\{100\}$. HRTEM images of inert gas precipitates have not been sufficiently well defined so as to allow precise determination of shapes and atomic amangements. This paper describes HRTEM results for $\mathrm{Xe}$ precipitates in $\mathrm{Al}$ and comparison to multi-slice image simulations based on a three-dimensional atomic model relating the precipitate and matrix. Furthermore, the experimental determination of the shape is shown using an off-Bragg illumination technique in HRTEM. 


\section{Experimental}

Thin Al disks, $3 \mathrm{~mm}$ in diameter, were mechanically cut from 4-9's starting material and annealed at $673 \mathrm{~K}$. TEM specimens were made by electro-polishing using an electrolyte of $\mathrm{HNO}_{3}: \mathrm{CH}_{3} \mathrm{OH}=1: 2$ at $253 \mathrm{~K}$. Ion implantations were carried out with $30 \mathrm{keV} \mathrm{Xe}$ at room temperature to a dose of $3 \times 10^{20}$ ions $/ \mathrm{m}^{2}$. Specimens were then annealed at $523 \mathrm{~K}$ for $0.5 \mathrm{~h}$ in vacuum to remove radiation damage in the $\mathrm{Al}$ matrix and to consolidate the $\mathrm{Xe}$ within precipitates. Templier [12] has reported that such annealing results in sharper precipitate images and sharper and more intense electron diffraction from the solid Xe in $\mathrm{Al}$.

Prior to HRTEM, the distribution of Xe precipitates was examined by conventional electron microscopy with a JEM-200CX. HRTEM was performed with a JEM ARM-1000 highvoltage TEM, operated at a voltage of $1 \mathrm{MV}$ with a spatial resolution of $0.13 \mathrm{~nm}$. Most of HRTEM observations were performed with the incident electron beam parallel to a $\langle 110\rangle_{\mathrm{A}}$ direction. Some observations were performed with a slightly tilted (less than 1 degree) electron beam condition to produce clear Xe images.

Xe precipitates in an Al lattice were modeled as a tetradecahedron with faces parallel to $\{111\}_{X_{e}}$ and $\{100\}_{\mathrm{Xe}}$ embedded in an Al cavity faceted on the same crystal planes. Based on the electron diffraction results, the lattice parameter of the FCC Xe crystal was chosen to be $50 \%$ larger than that of $\mathrm{Al}$. The precipitate size was chosen to be three coincident lattice spacings along each of the $\{111\}$ planes; namely 6 atoms for $\mathrm{Xe}$ and 9 atoms for $\mathrm{Al}$. The total thickness of the model is about $7 \mathrm{~nm}$ and the surface is normal to a $\{110\}_{\mathrm{Al}}$. Atomic relaxation was not considered at the $\mathrm{A} / \mathrm{Xe}$ interfaces. This model was constructed using a crystallographic package [13] on a Macintosh computer. Multi-slice image simulations were carried out to simulate the JEM ARM-1000 at $1000 \mathrm{keV}$, where the spherical aberration coefficient $C s$ is $2.6 \mathrm{~mm}$, the spread of defocus $\Delta$ is $10 \mathrm{~nm}$ and the beam semi-divergence $\alpha$ is $0.3 \mathrm{mrad}$. The defocus was varied from +10 to $-200 \mathrm{~nm}$. The Scherzer defocus for structure 
imaging is about $-55 \mathrm{~nm}$.

\section{Results and discussion}

Fig. 1 shows a set of diffraction contrast images of Xe precipitates in the thin region near the edge of a TEM specimen. In a normal bright field (BF) image (Fig. 1a), the precipitates appear as an unclear dark contrast. The FCC crystal structure of the solid precipitates is deduced from the extra spots in the selected area diffraction (SAD) pattern (Fig. 1b). Fig. 1c and Fig. 1d show a comparison between the BF image in the square area in Fig. la and a dark field (DF) image taken with a (111) Xe spot A marked in Fig. 1b. Coincidence of the two types of images indicates that the size of solid precipitates is less than $4 \mathrm{~nm}$.

HRTEM images of Xe precipitates are shown in Fig. 2. The incident electron beam is parallel to a [011] direction. Atoms appear as black dots in this image taken near Scherzer defocus. Two dimensional Moiré patterns along two $<111>$ and one $<100>$ directions are seen. Both the Moire patterns of HRTEM and the spacing of diffraction spots in the SAD pattern (Fig. 1b) indicate that the Xe precipitates have an FCC structure that is mesotactic with the $\mathrm{Al}$ matrix with a lattice spacing about $50 \%$ larger than that of Al. An enlarged image in Fig. $2 \mathrm{~b}$ displays the projection of the atomic structure of a single precipitate. The shape of the precipitate is not precisely determined due to a small variation in the contrast at the interface between the precipitate and the matrix. A similar observation was already reported by Donnelly et al. [9]. In general, the image of atomic positions at the coincident sites at the Al and Xe interface is clear.

There are several possible models [10-11] for insoluble inclusions I in an FCC matrix Mx. In most cases, the inclusion exhibits a cube-cube orientation relation with the matrix, with parallel close-packed planes and directions: $(111)_{\mathrm{Mx}} \|(111)_{\mathrm{I}}$ and $[110]_{\mathrm{Mx}} \|[110]_{\mathrm{I}}$. The inclusion's 
shape is typically a tetradecahedron, with faces parallel to dense $\{111\}$ and to $\{100\}$. The relative surface area of each class of planes reflects their relative surface energies. Typical examples of the results of multi-slice image simulations using such a model are shown in Fig. 3 for the [011] projection and objective defocus $D f$ of $-55,-100,-165 \mathrm{~nm}$. The simulated image at Df of $-55 \mathrm{~nm}$ (Scherzer defocus) is in qualitatively good agreement with the HRTEM image in Fig. 2b. The overlapping of $\mathrm{Al}$ and $\mathrm{Xe}$ atoms in the image is clearly demonstrated at the coincident atom positions. But white spots appear in the center portion of atomic images at the coincident positions. This may reflect the thickness of the model used in the simulation. Potter et al. [7] have reported the image simulations of a $\mathrm{Al} / \mathrm{Xe} / \mathrm{Al}$ layer structure and found a similar behavior for a partially coherent interface. The most interesting point of the simulation is the clarity of the interface of the precipitate, which was not observed in HRTEM. This is attributed to lack of ideal coincidence at the $\mathrm{Al} / \mathrm{Xe}$ interfaces and possible shifts of atomic positions within the precipitate.

To experimentally determine the shape of Xe precipitates, HRTEM was performed in offBragg electron illumination at different defocuses. One such image in [011] projection is shown in Fig. 4 along with the corresponding $\mathrm{SAD}$ pattern. This technique is common for the observation of small embedded particles [14]. One must be careful in the interpretation of such images because the defocus value was not Scherzer. This condition of electron beam and defocus caused the disappearance of $\mathrm{Al}$ lattice fringes. Two-dimensional projection of the $\mathrm{Xe}$ precipitates is determined to be a hexagon defined by $4\{111\}$ planes and $2\{100\}$ planes. This result is in good agreement with the model proposed in the image simulation. It is important to note that most of the precipitates in Fig. 4 show a high degree of crystalline perfection. However, some of the precipitates in Fig. 4 are not symmetrical along a $(100)_{X e}$ planes. The existence of defects in a Xe precipitate in $\mathrm{Al}$ was reported previously [9].

Based on the crystalline lattice images, the FCC lattice parameter $a_{x e}$ for the Xe precipitate is determined from the HRTEM images and the SAD patterns to be $0.595 \mathrm{~nm}$ which yields a 
molar volume of $3.2 \times 10^{-5} \mathrm{~m}^{3}$. The equilibrium pressure $P$ in the precipitate is estimated to be about $4.65 \times 10^{8} \mathrm{~Pa}$ using the isotherms of Anderson and Swenson [15] extrapolated to $300 \mathrm{~K}$. Assuming a spherical precipitate with a diameter $D$, the average free surface energy $\gamma$ which is balanced by the precipitate pressure $\mathrm{P}$ is given by $\gamma=\mathrm{PD} / 4$. The experimental values range from 0.1 to $0.5 \mathrm{~N} / \mathrm{m}$ which are, in all cases, smaller than the previously determined value 1.14 $\mathrm{N} / \mathrm{m}$ for $\mathrm{Al}[16]$.

\section{Conclusions}

High-resolution transmission electron microscopy (HRTEM) was carried out on Al TEM thinned specimens implanted with $30 \mathrm{keV} \mathrm{Xe}{ }^{+}$at room temperature to a dose of $3 \times 10^{20}$ ions $/ \mathrm{m}^{2}$ and subsequently annealed at $523 \mathrm{~K}$. The following conclusions are drawn:

(1) Below a size of approximately $4 \mathrm{~nm}$ in diameter, Xe precipitates are solid with an FCC crystal structure that is mesotactic with the Al lattice.

(2) In HRTEM along a [110] projection, the difference in lattice parameters of solid Xe and $\mathrm{Al}$ lattices produces a precipitate image dominated by a two-dimensional Moiré pattern that repeats in both the $<001>$ and $<111>$ every $3 \mathrm{Al}$ (or $2 \mathrm{Xe}$ ) lattice spacings.

(3) Multi-slice image simulations using a three-dimensional atomic model indicate that the precipitates are tetradecahedra with faces parallel to the dense $\{111\}$ planes and the $\{100\}$ planes.

(4) Off-Bragg illumination of the precipitates causes a disappearance of Al lattice fringes and produces precipitate images which are in gocd agreements with the atomic model. 


\section{References}

[1] S. Furuno, K. Hojou, K. Izui and T. Kino, J. Nucl. Mater. 155-157 (1988) 1149

[2] V. N. Chernikov, W. Kesternich, H. Ullmaier, J. Nucl. Mater. 227 (1996) 157

[3] R. C. Birtcher and C. Liu, J. Nucl. Mat. 165 (1989) 101

[4] R. C. Birtcher and W. Jäger, Ultramicroscopy 22 (1987) 267

[5] R. C. Birtcher, S. E. Donnelly and C. Templier, Phys. Rev. B 50 (1994) 764

[6] S. E. Donnelly and C. J. Rossouw, Physic. Res B13,(1986), 485

[7] D. I. Potter and C. J. Rossouw, J. Nucl.. Mat. ,161, (1989), 124 .

[8] E. Donnelly and J. Rossouw, Science. 230 (1985) 1272

[9] S. E. Donnelly, C. J. Rossouw and I. J. Wilson, Rad. Effects 97 (1986) 265

[10] L. Gråbæk, J. Bohr, H. H. Andersen, A. Johansen, E. Johnson, L. Sarholt-Kristensen and I. K. Robinson, Phys. Rev. B45 (1992) 2628

[11] S. Q. Xiao, E. Jhonson, S. Hindenberger, A. Johannsen, K. K. Bourdelle and U. Dahmen, J. microscopy 180 (1995) 61

[12] C. Templier, H. Garem, J. P. Riviere and J. Delafond, Nucl. Inst. and Meth. B 18 (1986) 24

[13] Total Resolution, 20 Florida Ave., Berkeley, California, USA

[14] N. Tanaka et.al., Ultramicroscopy 25 (1988) 241

[15] M. S. Anderson and C. A. Swenson, J. Phys. Chem. Solids. 36 (1975) 145

[16] K. H. Westmacott, R. E. Smallman and P. S. Dobson, Metal. Sci. J. 177 (1968) 2 


\section{Captions of figures}

Fig. 1. TEM micrographs of Xe precipitates in Al. The specimen was ion-implanted by $30 \mathrm{keV}$ $\mathrm{Xe}^{*}$ to a dose of $3 \times 10^{20}$ ions $/ \mathrm{m}^{2}$ at room temperature and subsequently annealed at $523 \mathrm{~K}$ for 0.5 h. (a) a bright field image near specimen edge, (b) a selected area diffraction (SAD) pattern, (c) an enlarged image of square area in Fig. 1a and (d) a corresponding dark field image of Fig. $1 \mathrm{c}$ using a spot $\mathrm{A}$ in Fig. 1b.

Fig. 2. High-resolution TEM (HRTEM) of Xe precipitates in Al, observed near Scherzer defocus. The incident electron beam is parallel to the [011] direction. (a) a low magnification micrograph and (b) an enlarged micrograph of square area in Fig. 2a.

Fig. 3. The results of multi-slice image simulation of Xe precipitates in Al matrix at different defocuses $\mathrm{Df}$. The solid $\mathrm{Xe}$ is modeled as a tetradecahedron having $8\{111\}$ planes and 4 $\{100\}$ planes. (a) $\mathrm{Df}=-55 \mathrm{~nm}$ (Scherzer defocus), (b) $\mathrm{Df}=-100 \mathrm{~nm}$ and (c) $\mathrm{Df}=-165 \mathrm{~nm}$.

Fig. 4. TEM results of $\mathrm{Xe}$ precipitates in $\mathrm{Al}$, observed at off-Bragg illumination and showing clear Xe lattice image. The incident electron beam is slightly tilted along the [011] direction. (a) a high-resolution TEM (HRTEM) image and (b) a SAD pattern. 


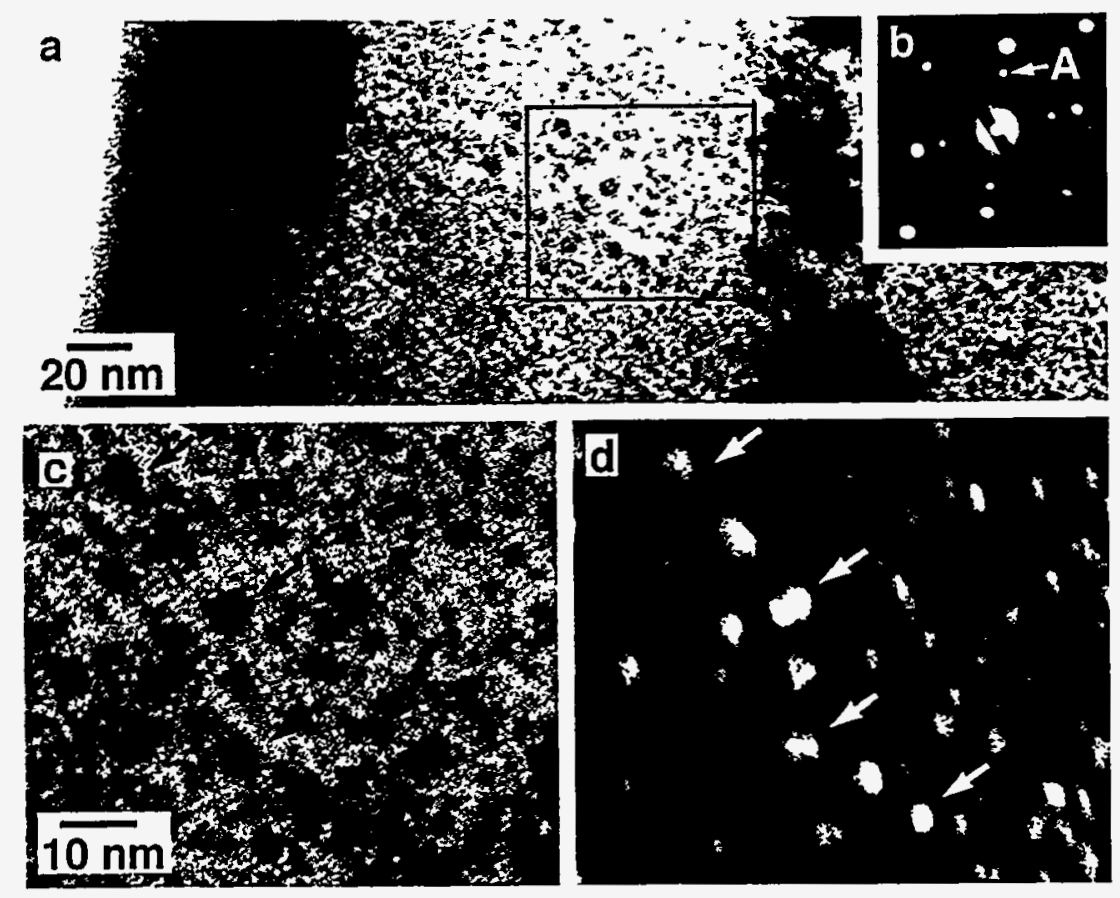

Figure 1.

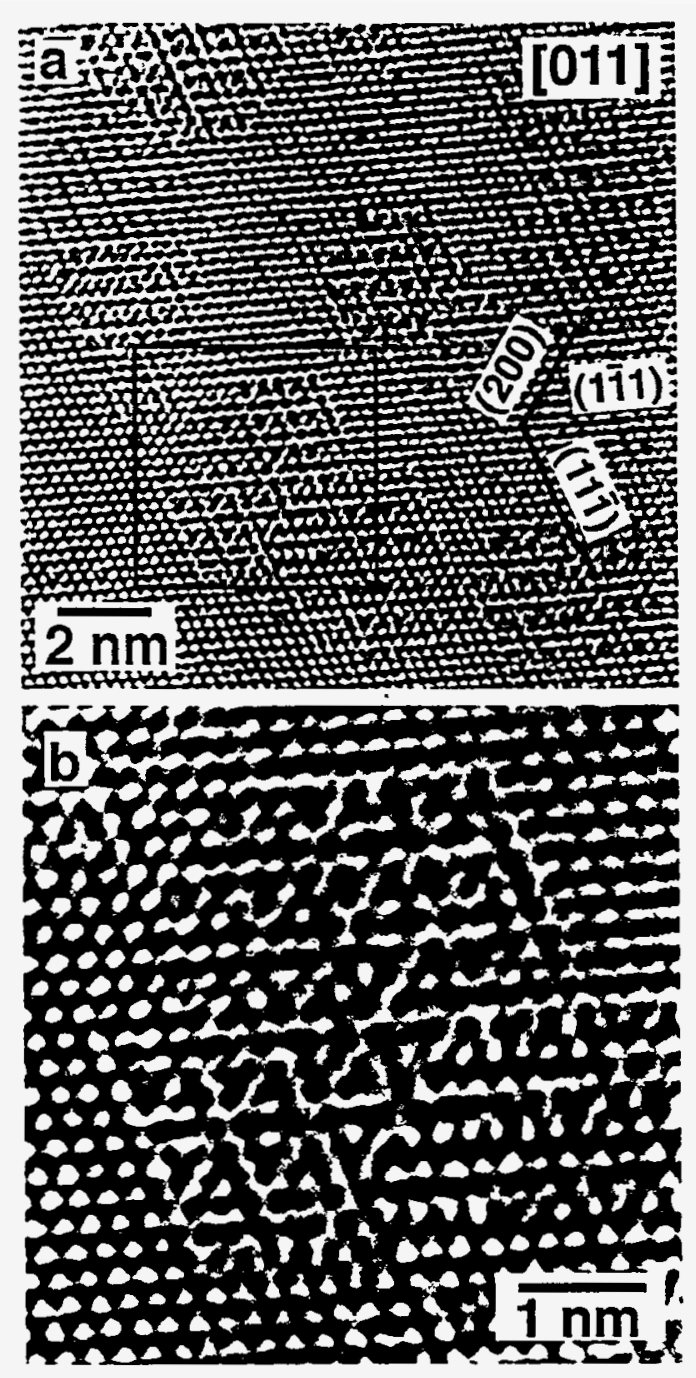

Figure 2.
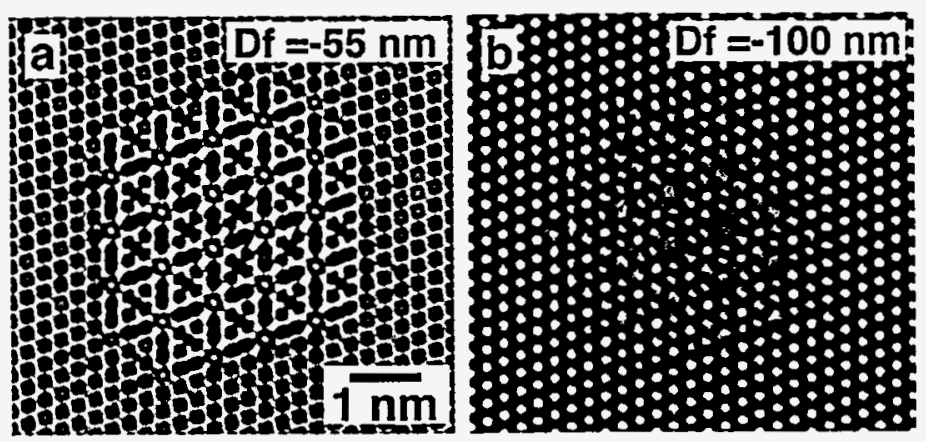

(1)

$\mathrm{Df}=-165 \mathrm{~nm}$

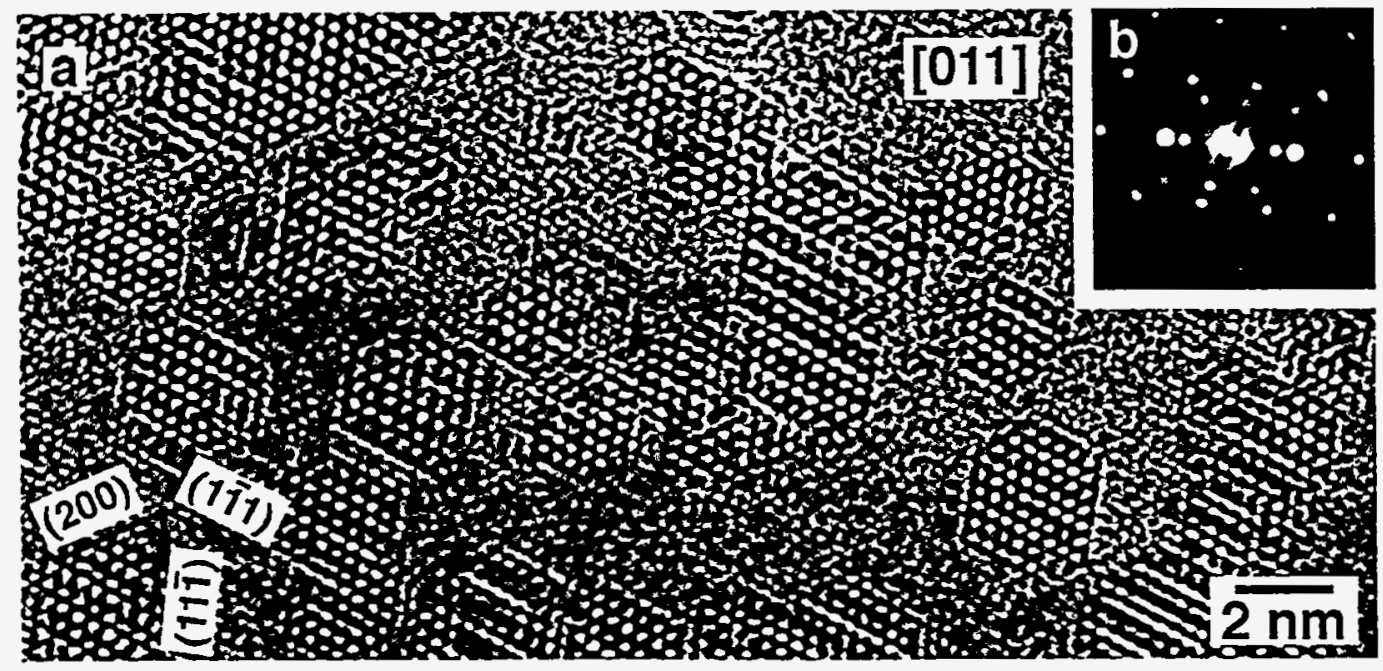

Figure 3.

Figure 4. 